\title{
Reproductive traits of pioneer gastropod species colonizing deep- sea hydrothermal vents after an eruption
}

by

\author{
Skylar Bayer \\ B.Sc. Marine Biology \\ Brown University, 2008 \\ SUBMITTED TO THE JOINT COMMITTEE OF BIOLOGICAL OCEANOGRAPHY \\ IN PARTIAL FULFILLMENT OF THE REQUIREMENTS FOR THE DEGREE OF \\ MASTER OF SCIENCE IN BIOLOGICAL OCEANOGRAPHY IN THE WHOI- \\ MIT JOINT PROGRAM AT THE MASSACHUSETTS INSTITUTE OF \\ TECHNOLOGY AND WOODS HOLE OCEANOGRAPHIC INSTITUTION
}

June 2011

(C) 2011 Skylar Bayer. All rights reserved.

The author hereby grants to MIT and WHOI permission to reproduce and to distribute publicly paper and electronic copies of this thesis document in whole or in part in any medium now known or hereafter created.

Signature of Author

Department of Biological Oceanography May 20, 2011

Certified by

Lauren Mullineaux

Senior Scientist of Biological Oceanography

Thesis Supervisor

Accepted by.

Simon Thorrold

Senior Scientist of Biological Oceanography Chairman, Joint Committee of Biological Oceanography 


\title{
Reproductive traits of pioneer gastropod species colonizing deep- sea hydrothermal vents after an eruption
}

\author{
by \\ Skylar Bayer \\ Submitted to the Joint Committee of Biological Oceanography on May 20, 2011 in \\ Partial Fulfillment of the Requirements for the Degree of Master of Science in Biological \\ Oceanography
}

\begin{abstract}
The colonization dynamics and life histories of pioneer species are vital components in understanding the early succession of nascent hydrothermal vents. The reproductive ecology of pioneer species at deep-sea hydrothermal vents may provide insight into their dispersal, population connectivity, and ability to colonize after disturbance. An opportunity to study the reproductive traits of two pioneer gastropod species, Ctenopelta porifera and Lepetodrilus tevnianus, presented itself in 2006 after an eruption on the East Pacific Rise (EPR) eliminated vent communities near $9^{\circ} 50^{\prime} \mathrm{N}$. Standard histological techniques were used to determine whether reproductive characteristics, such as timing of gamete release, fecundity, or time to maturation, differed from other vent gastropods in ways that might explain arrival of these two species as early colonizers. Both species exhibited two-component oocyte size frequency distributions that indicated they were quasi-continuous reproducers with high fecundity. In C. porifera, the oocyte size distributions differed slightly between two collection dates, suggesting that environmental cues may introduce some variability in gamete release. In samples collected within one year of the estimated eruption date, individuals in populations of both C. porifera and L. tevnianus were reproductively mature. The smallest reproducing C. porifera were $4.2 \mathrm{~mm}$ (males) and $5.4 \mathrm{~mm}$ (females) in shell length, whereas reproductive $L$. tevnianus were smaller $(2.3$ and $2.4 \mathrm{~mm}$ in males and females respectively). Most $C$ porifera in the population were large $(>6.0 \mathrm{~mm})$ compared to their settlement size and reproductively mature. In contrast, most $L$ tevnianus were small $(<$ $1.0 \mathrm{~mm}$ ) and immature. Reproductive traits of the two species are consistent with opportunistic colonization, but are also similar to those of other Lepetodrilus species and peltospirids at vents, and do not explain why these particular two species were the dominant pioneers. It is likely that their larvae were in high supply immediately after the eruption due to oceanographic transport processes from remote source populations.

Thesis Supervisor: Lauren Mullineaux

Title: Senior Scientist of Biological Oceanography
\end{abstract}




\section{Introduction}

Hydrothermal vent organisms are distinctive in their ability to persist in extremely unstable environments with strong chemical gradients. High concentrations of sulfides, iron, and trace metals $(\mathrm{Co}, \mathrm{Cu}, \mathrm{Pb}, \mathrm{Zn})$ occur in vent fluids (reviewed in Von Damm 1990). Endemic vent species populate regions of the deep sea associated with tectonic and volcanic activity that cause chemical-rich fluids up to $403^{\circ} \mathrm{C}$ to exit the seafloor (reviewed in Van Dover 2000). Vent fluids mix with the cooler ambient seawater creating environments highly variable in temperature and chemical composition (e.g., Johnson et al. 1986). The base of the food chain consists of chemoautotrophic microbes capable of using energy from reduced chemicals in the vent fluids to fix carbon (reviewed in Karl 1995). In addition to being chemically dynamic environments, vents are distributed discontinuously along mid-ocean ridges as dictated by underlying magma chamber and tectonic plate activity (reviewed in Fornari and Embley 1995). Vent species are bound to these patches of habitat separated by $10-100$ s of $\mathrm{km}$ along mid-ocean ridges (Tunnicliffe 1992; Chevaldonné et al. 1997). Thus the populations are fragmented, and the dynamics and persistence of the metapopulations depend on population connectivity as mediated by larval dispersal and recruitment (e.g., Neubert et al. 2006).

At fast-spreading ridges, such as the East Pacific Rise, eruptions occur on time scale of less than 100 years (MacDonald et al. 1980; Haymon et al. 1993). Geophysical models of fluid circulation beneath the basaltic crust reveal unsteady vent fluid convection (Watremez and Kervevan 1990), creating highly variable, transient habitats. Volcanic eruptions or tectonic quakes can obliterate entire communities and provide new substrata for colonization. Following such an event, the new basalt substratum may 
continue to change morphologically (Haymon et al. 1991) and vent fluids may vary in flux and chemical composition (Von Damm 1995; Butterfield et al. 1997) with associated increases or decreases in primary production (reviewed in Karl 1995). These eruptions are important disturbances that affect initial colonization patterns (reviewed in Tunnicliffe 1992), and genetic exchange (reviewed in Jollivet 1996) between vent sites.

The processes that influence how hydrothermal vent invertebrate populations are connected are still poorly understood. Since vent populations are physically fragmented, hydrodynamic transport (e.g., Chevaldonné et al. 1997; Kim and Mullineaux 1998; Mullineaux et al. 2003; Adams and Mullineaux 2008), larval lifespan (Marsh et al. 2001) and distribution within the water column (Mullineaux et al. 2005) are all thought to be important in long-range dispersal and on-site retention. Thus, vent inhabitants can be considered as being part of greater metapopulations (Vrijenhoek 1997; Jollivet et al. 1999; Neubert et al. 2006). A first step in understanding the complex patterns of connectivity within a metapopulation is to estimate the dispersal capabilities of the species (reviewed in Levin 2006). In the context of a nascent vent, the dispersal capabilities of pioneer species (those that colonize the site first) are of particular interest in understanding early successional processes and community structure. Because adult reproductive morphology can be used to infer details of a species' life history (Eckelbarger 1994), analyses of fecundity and spawning periodicity have increased our knowledge of the life histories of several prominent vent species (e.g., McHugh and Tunnicliffe 1994; Pendlebury 2005; Tyler et al. 2008). Therefore, studying reproductive characteristics of these pioneer species may provide insight into their dispersal, connectivity, and colonization dynamics. 
The ephemeral nature of hydrothermal vents would be expected to favor species that have r-type life history strategies including fast growth, early reproduction, and wide-spread larval dispersal (Van Dover et al. 1985; Young 2003). While most vent species reproduce continuously, reproductive strategies include a wide range of fertilization techniques, parental investment and larval feeding (Tyler and Young 1999; Young 2003). For instance vetigastropods (includes the genus Lepetodrilus) typically have a non-feeding planktotrophic larval stage. However, some vetigastropods brood their larvae within the pallial cavity and give birth to a crawling state (Bouchet and Warén 1994).

An opportunity to study primary succession and life-histories of pioneer species presented itself in 2006 after an eruption occurred on the East Pacific Rise (EPR) near $9^{\circ} 50^{\prime} \mathrm{N}$. Seismic data and camera footage indicated that newly released lava from the eruption wiped out previously existing communities and created new hydrothermal vents and substrata for colonization (Tolstoy et al. 2006; Cowen et al. 2007; Soule et al. 2007). Response cruises mobilized shortly after the event (Von Damm et al. 2006) and allowed biologists to study the early stages of faunal colonization. Although camera-based observations conducted after a prior (1991) eruption at this site documented successional patterns in the large, structure-forming species (Shank et al. 1998), this new eruption provided an opportunity to study a diverse group of species including those too small to observe in images.

Within 10 months of the eruption, colonization experiments (Mullineaux et al. 2010) revealed the appearance of the gastropod Ctenopelta porifera (Fig. 1a). This species is found at $13^{\circ} \mathrm{N}$ on the EPR (Warén and Bouchet 1993) but had not been 
observed in the benthos near $9^{\circ} 50^{\prime} \mathrm{N}$ (or anywhere else in the world's oceans). Another notable change was the prominence of the gastropod Lepetodrilus tevnianus (Fig. 1b) that had been much less abundant than congeners $L$. ovalis, L. pustulosus, L. cristatus, and $L$. elevatus prior to the eruption (McLean 1993). L. tevnianus typically is associated with the tubeworm Tevnia jerichonana and was first found at $11^{\circ} \mathrm{N}$ (McLean 1993) on the EPR although its range is now known to span from $11^{\circ} \mathrm{N}$ to $23^{\circ} \mathrm{S}$ (Johnson et al. 2008). The appearance of these two pioneer species, C. porifera and L. tevnianus, raises the question of how their life histories might facilitate early arrival after disturbance. Although general morphology of both species has been described in detail (C. porifera by Warén and Bouchet 1993; L. tevnianus by McLean 1993), no internal examinations or specific histological studies have been conducted on either. Ecological and reproductive studies have been conducted on the other species of Lepetodrilus on the EPR (Lepetodrilus ovalis, L elevatus, L. pustulosus, L. cristatus), the Mid-Atlantic Ridge (L. atlanticus), the Guaymas Basin (L. guaymasensis: Fretter 1988; McLean 1988; Pendlebury 2005), and the Juan de Fuca Ridge (L. fucensis: Fretter 1988; McLean 1988; Kelly and Metaxas 2007). On the EPR, L. elevatus had been the dominant gastropod species in established communities since the 1991 eruption (Shank et al. 1998; Van Dover 2000; Mullineaux et al. 2003), with other Lepetodrilus species (L. ovalis, L. pustulosus, L. cristatus) found in lower densities.

The main objective of this study was to utilize standard histological techniques to characterize the reproductive morphology of the pioneer gastropods C. porifera and $L$. tevnianus in order to determine whether they had higher fecundity, smaller oocyte size, or more variable reproductive timing than other related gastropod species inhabiting 
established vents in this region. We investigated the size at first reproduction to estimate how quickly new colonists could attain the ability to contribute progeny to the local community. We also quantified population structure (size distribution of colonists), which, in combination with minimum size of reproduction, provides an estimate of the proportion of the population that is reproductive and potentially contributing to local population growth. The broader goal of this approach is to gain insight into the processes influencing initial colonization at hydrothermal vents. 


\section{Methods}

Field sampling and initial analyses

Colonization surfaces were placed at P-vent $\left(9^{\circ} 50.28^{\prime} \mathrm{N}, 104^{\circ} 17.47^{\prime} \mathrm{W}\right)$ on the East Pacific Rise during post-eruption cruises aboard the $R V$ Atlantis in October 2006 (9 months after estimated eruption date) and December 2006 (11 months after eruption). The first set was recovered in December 2006 after a 1.5-month deployment and the second set in November 2007 after 11 months. The colonization surfaces (sandwiches) were comprised of six Lexan plates, each $10 \times 10 \times 0.6 \mathrm{~cm}$, separated by $0.9 \mathrm{~cm}$ cylindrical spacers. The surfaces were roughened by 50 -grit sandpaper, pitted with a metal press and banded with $0.1 \mathrm{~cm}$-deep grooves made with a wood saw. The plates and spacers were held together with cable ties to form a six-layered sandwich with a polypropylene braided line as a handle (Fig. 2). Sandwiches were deployed and recovered from individual collection compartments on the submersible Alvin similarly to the blocks described in Mullineaux et al. (2000). Once aboard $R V$ Atlantis, sandwiches were immediately transferred to buckets of $2^{\circ} \mathrm{C}$ seawater in the cold room for initial observations. Afterwards, the colonization surfaces and any attached colonists, as well as all detached individuals within the initial collection chamber that were retained in a 63 $\mu \mathrm{m}$ sieve, were processed as described below. Samples from the first recovery cruise (December 2006) were used to assess the size structure and reproductive status of $C$. porifera and L. tevnianus populations roughly one year after the 2006 eruption, and to describe reproductive morphology, oocyte size and fecundity (defined as total number of vitellogenic oocytes) in these species. Samples from the subsequent cruise (November 2007) were used to compare reproductive status of those populations a year later. 


\section{Recovery of colonization substrates}

During the first sandwich recovery cruise (December 2006), three sandwiches each were recovered and analyzed from hot $\left(18-30^{\circ} \mathrm{C}\right)$ and cool $\left(2-4^{\circ} \mathrm{C}\right)$ environments at $\mathrm{P}$ vent. The colonization surfaces and all attached and detached $(>63 \mu \mathrm{m})$ individuals were preserved in $80 \%$ ethanol for transport ashore. In the lab, the individual plates were separated, and lengths of all organisms were measured. Size was determined for $C$. porifera by measuring overall shell length (SL) on the dorsal side from the protoconch to the opposite lip of the shell. For L. tevnianus, the protoconch is not at the edge of the shell (Fig. 2b), so the maximum length across the dorsal side of the shell was used as shell length. Individuals were counted, identified to lowest taxonomic group possible, and stored in $95 \%$ ethanol in the laboratory. All C. porifera found were used for reproductive analysis, as well as all L. tevnianus $>2.0 \mathrm{~mm}$ in shell length. Small $(<2.0 \mathrm{~mm} \mathrm{SL}) L$. tevnianus were excluded from reproductive analyses because they were difficult to section, but were retained for analyses of population structure. Numbers of specimens used in each reproductive analysis, and selection criteria, are listed in Table 1.

During the second sandwich recovery cruise (November 2007), five sandwiches were recovered from the hot environment at P-vent using the same DSV Alvin protocol used in December 2006. Once inside the cold room, individual L. tevnianus adults greater than $2.0 \mathrm{~mm}$ were haphazardly selected off the plates (Table 1). All specimens of $C$. porifera found on the plates (16 specimens; Table 1) were used in reproductive analyses. Because so few individuals were found at P-vent, sandwiches from V-vent $\left(9^{\circ} 47.23^{\prime} \mathrm{N}\right.$, $\left.104^{\circ} 16.95^{\prime} \mathrm{W}\right)$, a vent approximately 4.8 kilometers away, were used to supplement the 
numbers (28 specimens; Table 1). For both species, all samples picked in the cold room were initially preserved for 4 days in $7 \%$ formalin and then transferred to $70 \%$ ethanol for transport back to the laboratory.

\section{Reproductive morphology and analyses}

All specimens examined for reproductive morphology (107 specimens; Table 1) were removed from their shells with forceps. Specimens were serially dehydrated using graded ethanol, cleared with xylene and embedded in molten histology paraffin wax using standard molds. Samples from December 2006 that initially had been preserved in $80 \%$ ethanol were transferred to formalin for four to five days prior to standard histology fixation steps. We refer to this as the "reverse" method of initial fixation of the sample, and it produced whole, undistorted sections with internal organs approximately the same size as in the 2007 samples (no apparent shrinkage) for reproductive analyses. Using standard haematoxylin and eosin procedures (reviewed in Kiernan 2008), paraffin blocks were cut transversely at $5 \mu \mathrm{m}$ thickness on a rotary microtome and stained. Assembling the serial sections for each individual and viewing them in sequence determined the general three-dimensional shape and location of the gonads.

From the December 2006 cruise our selection of male and female C. porifera specimens (22 individuals; Table 1) purposely spanned the SL size range of 5.0 - 10.0 $\mathrm{mm}$ for analyses of gonad morphology, oocyte size frequency and fecundity. Those with $\mathrm{SL}<5.0 \mathrm{~mm}$ were selected for size at first reproduction analysis but were not used for oocyte size frequency and fecundity analyses. From the November 2007 cruise we used all individuals recovered from P-vent for the analyses listed above and an additional 14 
selected individuals (spanning the same SL size range of those selected at P-vent, 5.0 $10.0 \mathrm{~mm}$ ) from $\mathrm{V}$-vent for fecundity analysis and male morphology only (Table 1). For L. tevnianus, males and females from each cruise were selected for analyses of gonad morphology, oocyte size and fecundity. Individuals ranging from $2.0-7.0 \mathrm{~mm}$ were used to examine size-specific reproduction (Table 1). Female and male gonad morphologies and fecundities were determined using a Zeiss Axiovert 200M microscope, and an AxioCam MRc5 camera, using Zeiss Axiovision version 4.4 Software.

\section{Size at first reproduction}

All specimens initially collected for reproductive morphology analysis were examined for sex, but cross-sectioning of the smaller specimens was used to assess the minimum size of reproductive maturity of each species. For $C$. porifera, all four individuals $<5.0 \mathrm{~mm}$ from December 2006 were used (none within this size range were recovered in November 2007), whereas for L. tevnianus, individuals in the $2.0-3.0 \mathrm{~mm}$ SL range were selected from the December 2006 samples (10 specimens; Table 1). All specimens used for size at first reproduction were serially cross-sectioned from the dorsal-side down through the foot of the animal. For L. tevnianus individuals $<3.0 \mathrm{~mm}$, it was nearly impossible to differentiate between sexes based on exterior morphology due to their small size. Thus, both sex and reproductive maturity were determined through cross-sectioning. Estimating size at first reproduction was of particular interest for the specimens collected in 2006 because it was used, in combination with shell size-frequency data, to estimate the proportion of the population that was reproductive within a year of the eruption. 


\section{Oocyte size-frequency analysis}

Individual females were selected based on being large $(>7.0 \mathrm{~mm}$, C. porifera; $>3.5 \mathrm{~mm}$, L. tevnianus) and therefore reproductively mature for analyses of oocyte size (Table 1). The gonads were observed in three transverse sections spaced roughly $100 \mu \mathrm{m}$ apart. Both pre-vitellogenic and vitellogenic oocytes were measured. Oocyte size frequencies per selected individual were calculated prior to averaging total size frequency of ranges of oocytes of selected gastropods for these analyses. Images were captured with an AxioCam MRc5 camera using Zeiss Axiovision version 4.4 Software. The feret diameters (diameter of the oocyte if it were a perfect circle) (as in Pendlebury 2005; Kelly and Metaxas 2007) of all oocytes with visible nuclei were calculated using ImageJ software (v. 1.39, National Institute of Health, Bethesda, Maryland, USA). A standard Pearson's Chi-Squared test using JMP (v. 1.5.2) was conducted on oocyte frequency data for from all specimens of each species to test for synchrony within populations. If the Chi-Squared test demonstrated that the populations were synchronous, then the oocyte size data were pooled across individuals for subsequent analyses.

In order to determine whether different cohorts could be distinguished in the size distributions, an Expectation-Maximization (EM) algorithm (McLachlan 1987; McLachlan and Peel 2000) was used to conduct a mixture model analysis on the data to test for two normal distributions of oocyte size. As an initial step, for both C. porifera and L. tevnianus and both sampling years, we tested the null hypothesis that log oocyte size follows a single normal distribution against the alternative hypothesis that it follows a mixture of two normal distributions with the same variance. We then proceeded to test for both species the null hypothesis that the parameters of the two-component normal 
mixture distribution were the same in both years (for each species) against the alternative hypothesis that they differed (details in Appendix A).

\section{Fecundity}

The total number of vitellogenic oocytes in each individual was used as the measure of fecundity in this study. Ten females of each species from each cruise were used in the analysis (Table 1). For C. porifera samples from November 2007, only six females were available for fecundity analysis from P-vent so the data were supplemented with four specimens from V-vent. Females of each species were selected to span the available size range in shell length (Table 1). For L. tevnianus the range was $3.0-7.0 \mathrm{~mm}$ (as those under $3.0 \mathrm{~mm}$ had lower quality sections) and for C. porifera it was $6.0-10.0 \mathrm{~mm}$. A two-step process was used to calculate fecundity, as in Pendlebury (2005). For each species, in the first step, three specimens were serially sectioned to find vitellogenic oocytes with visible nuclei (i.e. germinal vesicles), which were used to determine average vitellogenic oocyte diameter. This average diameter was then used as the spacing for cross-sectioning of the remaining specimens. Average vitellogenic oocyte size was $\sim 150$ $\mu \mathrm{m}$ for $C$. porifera and $\sim 100 \mu \mathrm{m}$ for L. tevnianus. The full gonad volume was sectioned for each specimen and oocytes found in each section were totaled. For both C. porifera and $L$. tevnianus, we used a regression model assuming a negative-binomial distribution to test for statistically significant differences of fecundity between years (details in Appendix B). 


\section{Population structure}

Size (SL) frequency data were compiled from all C. porifera and L. tevnianus individuals found at P-vent in December 2006 samples. Species-level identification of C. porifera was definitive for specimens of all sizes, but identification of L. tevnianus was definitive only for specimens $>2.0 \mathrm{~mm}$. Smaller individuals could be distinguished as Lepetodrilus sp., and we assume that they were L. tevnianus because no other species of that genus were found in the 2006 samples (this assumption is revisited in the Discussion section). In November 2007 samples, all C. porifera individuals found at P-vent and at V-vent were pooled for size frequency analyses because no significant difference in mean size was detected between the sites (two-sample t-test, $\mathrm{t}$-Ratio $=-1.73, \mathrm{dF}=14, \mathrm{P}<0.11 ; \mathrm{JMP}$ v. 1.5.2). A two-sample t-test was also conducted to compare $C$. porifera size between years. Size distributions of L. tevnianus from the December 2007 collections were not analyzed because only a subset of these individuals was measured. 


\section{Results}

Reproductive morphology and gametogenesis

Serial sections revealed that $C$. porifera is gonochoristic (for the detailed description and images of reproductive morphology, see Appendix C) and all analyzed individuals with the exception of one male (2.5 $\mathrm{mm} \mathrm{SL})$ had mature spermatozoa (males) or oocytes (females). The smallest male with mature testis had a shell length of $4.2 \mathrm{~mm}$ and the smallest female with mature oocytes had a length of $5.4 \mathrm{~mm}$ (previously recorded as 4.8 $\mathrm{mm}$ and $5.9 \mathrm{~mm}$, respectively, by Warén and Bouchet, 1993). Therefore the size at first reproduction was determined to be between 2.5 and $4.2 \mathrm{~mm}$ for males and less than 5.4 $\mathrm{mm}$ for females. Cross-sectioning of the sole immature male revealed tissue similar in appearance to that of the digestive gland (Appendix C) in the regions where the gonads would be in a reproductively mature adult.

All oocytes were tightly packed into the ovary. Oogonia developed in the epithelium of the ovary (Appendix C) and grew to 20-30 $\mu \mathrm{m}$ in diameter, when they developed into pre-vitellogenic oocytes as distinguished by their visible nuclei and dark purple staining. Vitellogenesis generally began when oocytes are 60-70 $\mu \mathrm{m}$. In most samples, vitellogenic oocytes typically reached a maximum size of 230-250 $\mu \mathrm{m}$ (a few of the oocytes were $>300 \mu \mathrm{m}$, probably due to distortion).

Cross-sectioning revealed that L. tevnianus also is gonochoristic (Appendix C), and all adults with shells larger than $2.4 \mathrm{~mm}$ had mature spermatozoa (males) and ovary (females). Of the male specimens selected for first size at reproduction studies (2.2 to 2.4 $\mathrm{mm}$ ), only those $2.3 \mathrm{~mm}$ or larger were reproductively mature. Of the female specimens ( 2.2 to $2.6 \mathrm{~mm}$ ), only those $2.4 \mathrm{~mm}$ and larger were mature. In immature individuals, 
gonads were difficult to distinguish from the digestive gland (Appendix C). Light histological sections of L. tevnianus stained with haematoxylin and eosin (Appendix C) illustrate that the ovary occupies a large volume of the gastropod (approximately onethird) and that oocytes are tightly packed throughout the ovary. Oogonia develop in the germinal epithelium of the ovary and grow until they are about $20 \mu \mathrm{m}$ when they develop into pre-vitellogenic oocytes (Appendix C). These oocytes begin to develop into mature vitellogenic oocytes (characterized by acidophilic granular cytoplasm) between 50-60 $\mu \mathrm{m}$, generally reaching a maximum of 130-150 $\mu \mathrm{m}$ (although a few rare oocytes, two of 1497 measured, reached $210 \mu \mathrm{m})$. The general shape of the gonads in males, and the location relative to the stomach, digestive gland and foot, were similar to those of the ovary in females (Appendix C).

\section{Oocyte size-frequency}

Oocyte size distributions did not vary significantly among individuals for either $C$.

porifera $\left(\chi^{2}=550, \mathrm{dF}=25, \mathrm{P}>0.24\right)$ or L. tevnianus $\left(\chi^{2}=255, \mathrm{dF}=17, \mathrm{P}>0.24\right)$. Size distributions pooled over multiple individuals of C. porifera (Fig. 3a, b) and L. tevnianus (Fig. 3c, d) appeared to have more than a single normally distributed size component. The mixture model analysis demonstrated evidence of two size components in the oocyte size frequency data for both species (Table 2), possibly reflecting two different cohorts of oocytes. The null hypothesis that log oocyte size follows a single normal distribution was rejected in all cases except for L. tevnianus from November 2007 (details in Appendix A). We therefore assumed conservatively that in all cases the distribution of $\log$ size follows a two-component normal mixture. This is a conservative assumption in 
the sense that if it is incorrect, it will not affect the validity of the test. For both species the null hypothesis that the parameters of the two-component normal mixture distribution were the same in both years was tested against the alternative hypothesis of difference between years. The results of fitting the model under the second null hypothesis are given in Table 3 (detailed results in Appendix A). After running the EM algorithm, the second null hypothesis was rejected for both species $(\mathrm{P}=0.002$ for $C$. porifera and $\mathrm{P}=0.03$ for L. tevnianus). It is important to note, however, that the test is quite powerful for these sample sizes, and even small differences between the parameters may lead to the rejection of the null hypothesis that they are the same in both years.

Using the results of the mixture-model analysis, the two components of oocyte size in C. porifera had means of $81.5 \mu \mathrm{m}$ and $148.4 \mu \mathrm{m}$ for both 2006 and 2007 (log sizes shown in Table 2). In C. porifera, pre-vitellogenic oocytes (defined as all those $<60 \mu \mathrm{m}$ ) accounted for approximately $12 \%$ of all oocytes from December 2006 and approximately $20 \%$ from November 2007. The two components of oocyte size in L. tevnianus had means of $54.6 \mu \mathrm{m}$ and $99.5 \mu \mathrm{m}$ for 2006 and $54.6 \mu \mathrm{m}$ and $81.5 \mu \mathrm{m}$ for 2007. In $L$. tevnianus, oocytes in the pre-vitellogenic stage (those $<40 \mu \mathrm{m}$ ) comprised approximately $5 \%$ of oocytes.

\section{Fecundity}

Fecundity in both species was relatively high ( $>500$ vitellogenic oocytes in the largest females) and increased roughly exponentially with size (Fig. 4). Size-specific fecundity in L. tevnianus was higher than in C. porifera because it matured at a smaller size, but fecundity in the largest individuals (509 oocytes in C. porifera and 596 in L. tevnianus) 
was similar. The relationship between fecundity and shell length was roughly exponential for both species (Fig. 4). Regression model analysis revealed no difference between years in this relationship for $C$. porifera $(\mathrm{F}-\mathrm{ratio}=0.13, \mathrm{P}=0.88)$ but a significant difference for L. tevnianus (F-ratio $=5.51, \mathrm{P}=0.02)($ details in Appendix B).

\section{Population structure}

Distributions of shell length for both species were determined from all individuals found on sandwiches collected in December 2006 (Fig. 5). Sizes of C. porifera in December 2006 ranged from $2.5-8.6 \mathrm{~mm}$. All individuals but one (98\% of population) were reproductively mature (Fig. 5b). Sizes of C. porifera found at P-vent in November 2007 ranged from $7.0-10.7 \mathrm{~mm}$; sizes at $\mathrm{V}$-vent ranged from 5.9 to $10.7 \mathrm{~mm}$ (Fig. 5c). All individuals in these samples were assumed to be reproductively mature based on the estimated size at first reproduction for ( $4.2 \mathrm{~mm}$ for males, $5.4 \mathrm{~mm}$ for females). The twosample t-test revealed no statistical significance in size distribution between samples from P-vent and V-vent (November 2007) $(\mathrm{t}$-Ratio $=-1.73, \mathrm{dF}=14, \mathrm{P}<0.11)$. However, there was a statistically significant difference in the size distributions of C. porifera between $2006(\mathrm{P}-\mathrm{vent}$ only) and $2007(\mathrm{P}$-vent and V-vent pooled $)(\mathrm{t}$-Ratio $=-5.99, \mathrm{dF}=$ 42, $\mathrm{P}<0.001)$.

Sizes of L. tevnianus (including Lepetodrilus specimens too small to identify to species, but assumed to be L. tevnianus as no other species of this genus was found among samples collected in the area) ranged from 0.2 to $7.0 \mathrm{~mm}$ (Fig. 5a). Using $2.4 \mathrm{~mm}$ as a conservative estimate of size at first reproduction (males may be reproducing between 2.3 and $2.4 \mathrm{~mm}$ and sexes are difficult to distinguish at these sizes), 
approximately $22 \%$ of the population was reproductively mature and potentially contributing to the production of larvae (Fig. 5a). 


\section{Discussion}

Histological analysis revealed that reproductive traits, such as quasi-continuous spawning, of both $C$. porifera and L. tevnianus are similar to related species within their respective families (Berg 1985, Fretter 1988; Pendlebury 2005; Kelly and Metaxas 2007) (Table 4). Since we observed no unique reproductive or life-history traits for vent gastropods in either species, we do not think that their appearance as pioneers in the posteruption community at $9^{\circ} \mathrm{N}$ is due to unusual reproductive adaptations. Reproductive traits of these species and related Lepetodrilus spp. and peltospirids indicate that they are all potentially opportunistic vent colonizers.

For both $C$. porifera and L. tevnianus, vitellogenic oocyte size and oocyte size at onset of vitellogenesis fell within the range of other EPR species (Table 4), but values generally were greater than those reported in Pendlebury (2005). Gonad location of $C$. porifera was similar to that of $R$. concentrica. When comparing oocyte sizes between species, it is important to note that values reported for a particular species vary between authors. For example, Fretter (1988) and Berg (1985) reported values for $R$. concentrica from $13^{\circ} \mathrm{N}$ and $21^{\circ} \mathrm{N}(\mathrm{EPR})$ that were considerably larger than those reported from $9^{\circ} \mathrm{N}$ by Pendlebury (2005).

The two-component distribution of oocyte sizes from multiple individuals indicates that gametogenesis is most likely quasi-continuous in both $C$. porifera and $L$. tevnianus. The low variation in oocyte size distribution among individuals suggests that reproduction was not asynchronous within the populations of either species. Oocyte size distributions in quasi-continuous spawners are expected to vary slightly over time, as the mature oocytes are released (reviewed in Eckelbarger and Watling 1995). The slight, but 
significant, difference observed between years in oocyte size distributions of both $C$.

porifera and L. tevnianus may indicate responses to changes in the surrounding microenvironment, but they are very subtle when compared to the reproductive periodicity observed in discontinuous spawners that respond to large-scale environmental shifts such as detritus pulses (reviewed in Tyler et al. 1994). This synchronous, quasi-continuous, reproduction is consistent with the reproductive cycles of other vent molluscs (reviewed in Tyler et al. 1994; Tyler and Young 1999; Pendlebury 2005; Kelly and Metaxas 2007; Tyler et al. 2008).

The present study demonstrates that $L$. tevnianus matures at a smaller size than $C$. porifera and has higher fecundity at any given size. These results are consistent with Pendlebury's (2005) observed differences between other Lepetodrilus spp. and peltospirids on the EPR. We do not know whether Lepetodrilus spp. reproduce at an earlier age than peltospirids because the size-to-age relationships in these species are unknown. Still, elevated levels of fecundity at small sizes are indicative of pioneer or weed species (Barrett 1992), leading to an expectation that Lepetodrilus spp., but not peltospirids, should be pioneer colonists at EPR vents. Observations following the 2006 eruption (Mullineaux et al. 2010) show this not to be the case, as the early colonists included a peltospirid (C. porifera), but not the full suite of pre-eruption Lepetodrilus species. The difference between years in the size-fecundity relationship for L. tevnianus is difficult to interpret, given the low number of individuals sampled.

Another difference worth noting between the two species is the preponderance of small $(<4.0 \mathrm{~mm})$ individuals in $L$. tevnianus but not $C$. porifera populations, despite a size at recruitment of $<0.4 \mathrm{~mm}$ for both $(179 \mu \mathrm{m}$ in L. tevnianus and $290-325 \mu \mathrm{m}$ in $C$. 
porifera: Mills et al. 2009; Warén and Bouchet 1993). If some of the smallest $(<2.0 \mathrm{~mm})$ Lepetodrilus individuals are species other than L. tevnianus, then our calculations of the proportion of the population that are reproductive (22\%) would be an underestimate.

The average size of C. porifera individuals was significantly larger in 2007 than 2006 (Fig. 5) and this apparent absence of new recruits in 2007 could be a consequence of a high juvenile growth rate, a high juvenile mortality rate or discontinuous recruitment. We think that the last possibility, discontinuous larval recruitment, is most likely because it is consistent with measures of larval supply of $C$. porifera after the 2006 eruption. Their larval numbers were high shortly after the eruption in July 2006, but had declined substantially by October 2006 (Mullineaux et al. 2010). Thus, at the time of our collections in December 2006 and November 2007, larvae of C. porifera may not have been recruiting in large numbers. All individuals from both years were large enough (> $5.4 \mathrm{~mm}$ in females and $>4.2 \mathrm{~mm}$ in males) to be reproductively mature, with the single exception of the $2.5 \mathrm{~mm}$ male collected in 2006 , so the coarse resolution in our estimate of size at first reproduction did not affect calculations of reproductive maturity at the population level.

Our results indicate that $C$. porifera and $L$. tevnianus are quasi-continuous reproducers with only slight (but significant) variations in oocyte size distributions between years. Because these variations were slight, we suspect that variation in larval supply due to physical processes may have played a role in these species' colonization after the 2006 EPR eruption. Larval abundance and supply can be temporally variable at vents due to physical oceanographic transport (Metaxas 2004; Mullineaux et al. 2005; Adams and Mullineaux 2008), and the pioneer colonists after a major disturbance may 
simply represent whatever species are available in the plankton at that time. Variation in larval supply could be caused by reversals in along-axis currents (e.g., Chevaldonné et al. 1997; Marsh et al. 2001; Adams and Mullineaux 2008) or the passage of mesoscale eddies (e.g., Adams 2007). If this type of oceanographically-driven variation in larval supply determines the species composition of pioneers, the interaction between earlyarriving species' reproductive characteristics and episodic oceanographic events may be a principal driver of the successional trajectory in nascent vent communities. 


\section{Acknowledgements}

We thank the captain and crew of the $R V$ Atlantis and the members of the Alvin group aboard cruises AT15-14 and AT15-26. We are grateful to Andreas Thurnherr, Susan Mills, Stace Beaulieu, Carly Strasser, Benjamin Walther and Nika Staglicic for assistance at sea and collection of samples. Paula Weston and Michele Gardner of the Brown University Molecular Pathology Core Lab contributed greatly to the histology processing of samples. This work was supported by National Science Foundation grant OCE0424953 to Mullineaux and by funds provided through the WHOI Summer Student Fellowship program and the Brown University Ecology and Evolutionary Biology Department to Bayer. We gratefully acknowledge comments from three anonymous reviews who aided in improving this manuscript. 


\section{References}

Adams, DK (2007) Influence of hydrodynamics on the larval supply to hydrothermal vents on the East Pacific Rise. PhD thesis. Woods Hole Oceanographic Institution

Adams, DK, LS Mullineaux LS (2008) Supply of gastropod larvae to hydrothermal vents reflects transport from local larval sources. Limnol Oceanogr 53(5): 1945-1955

Barrett, SCH (1992) Genetics of weed invasions. In: Applied Population Biology. Monographiae Biologicae, Springer Netherlands, pp 91-119

Berg CG (1985) Reproductive strategies of mollusks from abyssal hydrothermal vent communities. Biol Soc Wash Bull 6: 185-197

Bouchet, P and A Warén (1994) Ontogenetic migration and dispersal of deep-sea gastropod larvae. Pages 98-117 in C. M. Young and K. J. Eckelbarger, eds. Reproduction, larval biology, and recruitment of the deep- sea benthos. Columbia University Press, New York.

Butterfield D, Jonasson I, Massoth G, Feely R, Roe K, Embley R, Holden K, McDuff R, Lilley M, Delaney J (1997) Seafloor eruptions and evolution of hydrothermal fluid chemistry. Philos Trans R Soc Lond B Biol, Ser (A Math, Phys, Sci) 335: 369-386

Chevaldonné P, Jollivet D, Vangriesheim A, Desbruyeres D (1997) Hydrothermal vent alvinellid polychaete dispersal in the eastern Pacific. 1. Influence of vent distribution, bottom currents, and biological patterns. Limnol Oceanogr 42(1): 6780

Cowen JP, Fornari DJ, Shank TM, Love B, Galzer B, Treusch A, Holmes RC, Soule SA, Baker ET, Tolstoy M, Pomranig KR (2007) Volcanic eruptions at East Pacific Rise near $9^{\circ} 50^{\prime} \mathrm{N}$. Eos Trans Am Geophys Union 88 (7): 81-83 
Eckelbarger KJ, Watling L (1995) Role of phylogenetic constraints in determining reproductive patterns in deep-sea invertebrates. Invertebr Biol 114: 256-269

Eckelbarger KJ (1994) Diversity of metazoan ovary and vitellogenic mechanisms: implications for life history theory. Proc Biol Soc Wash 107: 193-218

Fornari DJ, Embley RW (1995) Tectonic and volcanic controls on hydrothermal processes at the mid-ocean ridge: an overview based on near-bottom and submersible studies. Geophys Monogr 91: 1- 46

Fretter V (1988) New archaeogastropod gastropods from hydrothermal vents; superfamily Lepetodrilacea II. Anatomy. Philos Trans R Soc Lond B Biol Sci $319: 33-82$

Haymon RM, Fornari DJ, Edwards MH, Carbotte S, Wright D, Macdonald KC (1991) Hydrothermal vent distribution along the East Pacific Rise crest $\left(9^{\circ} 09^{\prime}-54^{\prime} \mathrm{N}\right)$ and its relationship to magmatic and tectonic processes on fast-spreading mid-ocean ridges. Earth Planet Sci Lett 104: 513-534

Haymon RM, Fornari DJ, Von Damm KL, Lilley MD, Perfit MR, Edmond JM, Shanks III WC, Lutz RA, Grebmeier JM, Carbotte S, Wright D, McLaughlin E, Smith M, Beedle N, Olson E (1993) Volcanic eruption of the mid-ocean ridge along the East Pacific Rise crew at $9^{\circ} 45-52^{\prime} \mathrm{N}$ : direct submersible observations of sea-floor phenomena associated with an eruption event April, 1991. Earth Planet Sci Lett 119:85-101

Johnson KS, Beehler CL, Sakamoto-Arnold CM, Childress JJ (1986) In situ measurements of chemical distributions in a deep-sea hydrothermal vent field. Science 231: 1139-1141 
Johnson SB, Young CR, Jones WJ, Warén A, Vrijenhoek RC (2008) DNA barcoding of Lepetodrilus limpets reveals cryptic species. J Shell Res 27(1): 43-51

Jollivet D (1996) Specific and genetic diversity at deep-sea hydrothermal vents: An overview. Bio divers Conserv 5:1619-1653

Jollivet D, Chevaldonné P, Planque B (1999) Hydrothermal-vent alvinellid polychaete dispersal in the eastern Pacific. 2. A metapopulation model based on habitat shifts. Evolution 53 (4): 1128-1142

Karl DM (1995) The microbiology of deep sea hydrothermal vents. CRC, New York Kelly NE, Metaxas A (2007) Influence of habitat on the reproductive biology of the deep-sea hydrothermal vent gastropod Lepetodrilus fucensis (Vetigastropoda: Mollusca) from the Northeast Pacific. Mar Biol 151: 649-662

Kiernan JA (2008) Histological and Histochemical Methods: Theory and Practice ( $4^{\text {th }}$ ed.) Bloxham, United Kingdom

Kim SL, Mullineaux LS (1998) Distribution and near-bottom transport of larvae and other plankton at hydrothermal vents. Deep-Sea Res II 45: 423-440

Levin LA (2006) Recent progress in understanding larval dispersal: new directions and digressions. Soc Integr Comp Biol 46(3): 282-297

MacDonald KC, Becker K, Spiess FN, Ballard RD (1980) Hydrothermal heat flux of the "black smoker" vents on the East Pacific Rise. Earth Planet Sci Lett 48:1-7

Marsh AG, Mullineaux LS, Young CM, Manahan DT (2001) Larval dispersal potential of the tubeworm Riftia pachyptila at deep-sea hydrothermal vents. Nature 411: 7780

Metaxas A (2004) Spatial and temporal patterns in larval supply at hydrothermal vents on 
the northeast Pacific Ocean. Limnol Oceanogr 49: 1949-1956

McLachlan G, Peel D (2000) Finite mixture models. Wiley-Interscience, New York McLachlan G (1987) On bootstrapping the likelihood ratio test statistic for the number of components in a normal mixture. Appl Stat 36: 318-324

McLean JH (1988) New archaeogastropod limpets from hydrothermal vents; superfamily Lepetodrilacea I. Systematic descriptions. Philos Trans R Soc Lond B Biol Sci 319: $1-32$

McLean JH (1993) New species and record of Lepetodrilus (Vetigastropoda: Lepetodrilidae) from hydrothermal vents. Veliger 36: 27-35

McHugh D, Tunnicliffe V (1994) Ecology and reproductive biology of the hydrothermal vent polychaete Amphisamytha galapagensis (Ampharetidae). Mar Ecol Prog Ser 106: $111-120$

Mills SW, Beaulieu SE, Mullineaux LS (2009) Photographic identification guide to larvae at hydrothermal vents. Woods Hole Oceanogr Inst Tech Rept WHOI-200905

Mullineaux LS, Adams DK, Mills SW, Beaulieu SE (2010) Larvae from afar colonize deep-sea hydrothermal vents after a catastrophic eruption. Proc Natl Acad Sci 107(17): 7829-7834

Mullineaux LS, Fisher CR, Peterson CH, Schaeffer SW (2000) Tubeworm succession at hydrothermal vents: use of biogenic cues to reduce habitat selection error? Oecologia 123(2): 275-284 
Mullineaux LS, Mills SW, Sweetman AK, Beaudreau AH, Metaxas A, Hunt HL (2005) Vertical, lateral and temporal structure in larval distributions at hydrothermal vents. Mar Ecol Prog Ser 293: 1-16

Mullineaux LS, Peterson CH, Micheli F, Mills SW (2003) Successional mechanism varies along a gradient in hydrothermal fluid flux at deep-sea vents. Ecol Monogr 73 (4): $523-542$

Neubert MG, Mullineaux LS, Hill MF (2006) A metapopulation approach to interpreting diversity at deep-sea hydrothermal vents. In: JP Kritzer, PE Sale, (eds), Marine Metapopulations. (Elsevier, London), pp 321-350

Pendlebury, SJD (2005) Ecology of Hydrothermal Vent Gastropods. PhD thesis. School of Ocean and Earth sciences, Southampton

Shank TM, Fornari DJ, Von Damm KL, Lilley MD, Haymon RM, Lutz R (1998)

Temporal and spatial patterns of biological community development at nascent deep-sea hydrothermal vents (9॰50’N, East Pacific Rise) Deep-Sea Res II 45: 464515

Soule SA, Fornari DJ, Perfit MR, Rubin K (2007). New insights into mid-ocean ridge volcanic processes from the $2005-2006$ eruption of the East Pacific Rise, $9^{\circ} 46^{\prime} \mathrm{N}-$ $9^{\circ} 56^{\prime} \mathrm{N}$. Geology 35: $1079-1082$

Tolstoy M, Cowen JP, Baker ET, Fornari DJ, Rubin KH, Shank TM, Waldhauser F, Bohnenstiehl DR, Forsyth DW, Holmes RC, Love B, Perfit MR, Weekly RT, Soule SA, Glazer B (2006) A sea-floor spreading event captured by seismometers.

Science 314: 1920-1922 
Tyler PA, Pendlebury S, Mills SW, Mullineaux LS, Eckelbarger KJ, Baker M, Young CM (2008) Reproduction of gastropods from vents on the East Pacific Rise and the Mid-Atlantic Ridge. J Shellfish Res 27 (1): 107-118

Tyler PA, Young CM (1999) Reproduction and dispersal at vents and cold seeps. J Mar Biol Ass UK 79: 193-208

Tyler PA, Campos-Creasey LS, Giles LA (1994) Environ- mental control of quasicontinuous and seasonal reproduction in deep-sea benthic invertebrates. In: Young $\mathrm{CM}$ and Eckelbarger KJ (eds), Reproduction, Larval Biology and Recruitment of the Deep-Sea Benthos: pp. 158-178. Columbia University Press, New York

Van Dover CL (2000) The ecology of deep-sea hydrothermal vents. Princeton University Press, Princeton

Van Dover CL, Factor JR, Williams AB, Berg CJ (1985) Reproductive patterns of decapod crustaceans from hydrothermal vents. Biol Soc Wash Bull 6: 223-227

Von Damm (1990) Seafloor hydrothermal activity: black smoker chemistry and chimneys. Annu Rev Earth Planet Sci 18:173-204.

Von Damm KL (1995) Controls on the chemistry and temporal variability of seafloor hydrothermal fluids. In: SE Humphris, RA Zierenberg, LS Mullineaux and RE Thornson (eds), Seafloor Hydrothermal systems: physical, chemical, biological, and geological interactions: Am Geophys Union Monogr 91: 222-247

Von Damm KL, Bates MJ, Carmichael SK, Meana-Prado F, McDermott JM (2006) Response of the 9-10N EPR hydrothermal systems to recent volcanic eruptions, Eos Trans Am Geophys Union, 87(52), Fall Meet Suppl, Abstract V13C-02 
Vrijenhoek RC (1997) Gene flow and genetic diversity in naturally fragmented metapopulations of deep-sea hydrothermal vent animals. J Hered 88: 285-293

Warén A, Bouchet P (1993) New records, species, genera and a new family of gastropods from hydrothermal vents and hydrocarbon seeps. Zool Scrip 22: 1-90

Watremez P, Kervevan C (1990) Origines des variations de l'activite hydrothermale: premiers elements de response d'un modele numerique simple. C R Acad Sci Paris, Ser II 311:153-158

Young CM (2003) Reproduction, development and life-history traits. In: Tyler PA (ed) Ecosystems of the deep oceans. Elsevier, Amsterdam, pp 381- 426 


\section{Figures}

Fig. 1 Images of adult Ctenopelta porifera (a) and Lepetodrilus tevnianus (b). Dotted line (b) indicates shell length measurement in L. tevnianus .

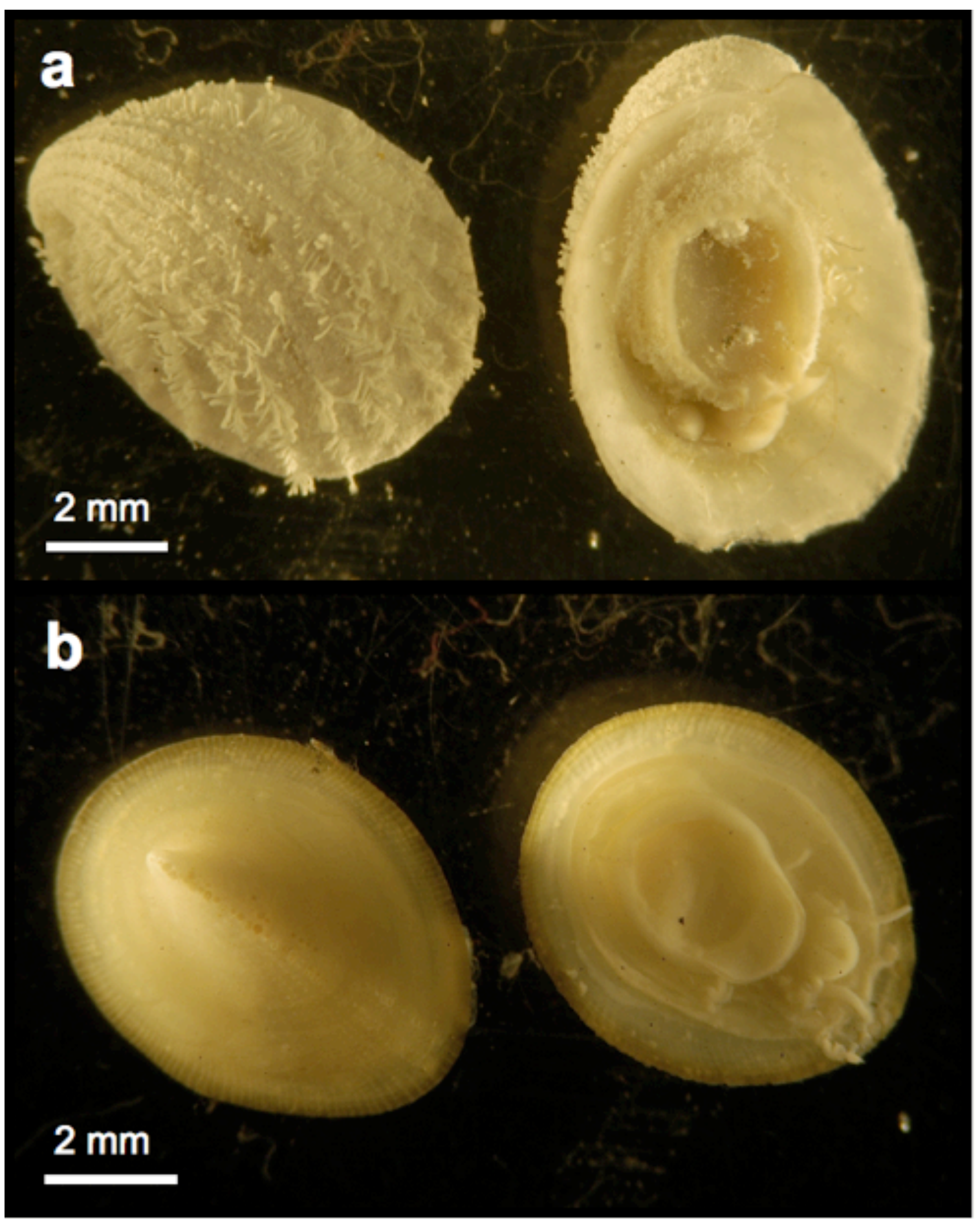


Fig. 2 Photo of sandwich (10 $\mathrm{cm}$ on a side) being deployed by DSV Alvin.

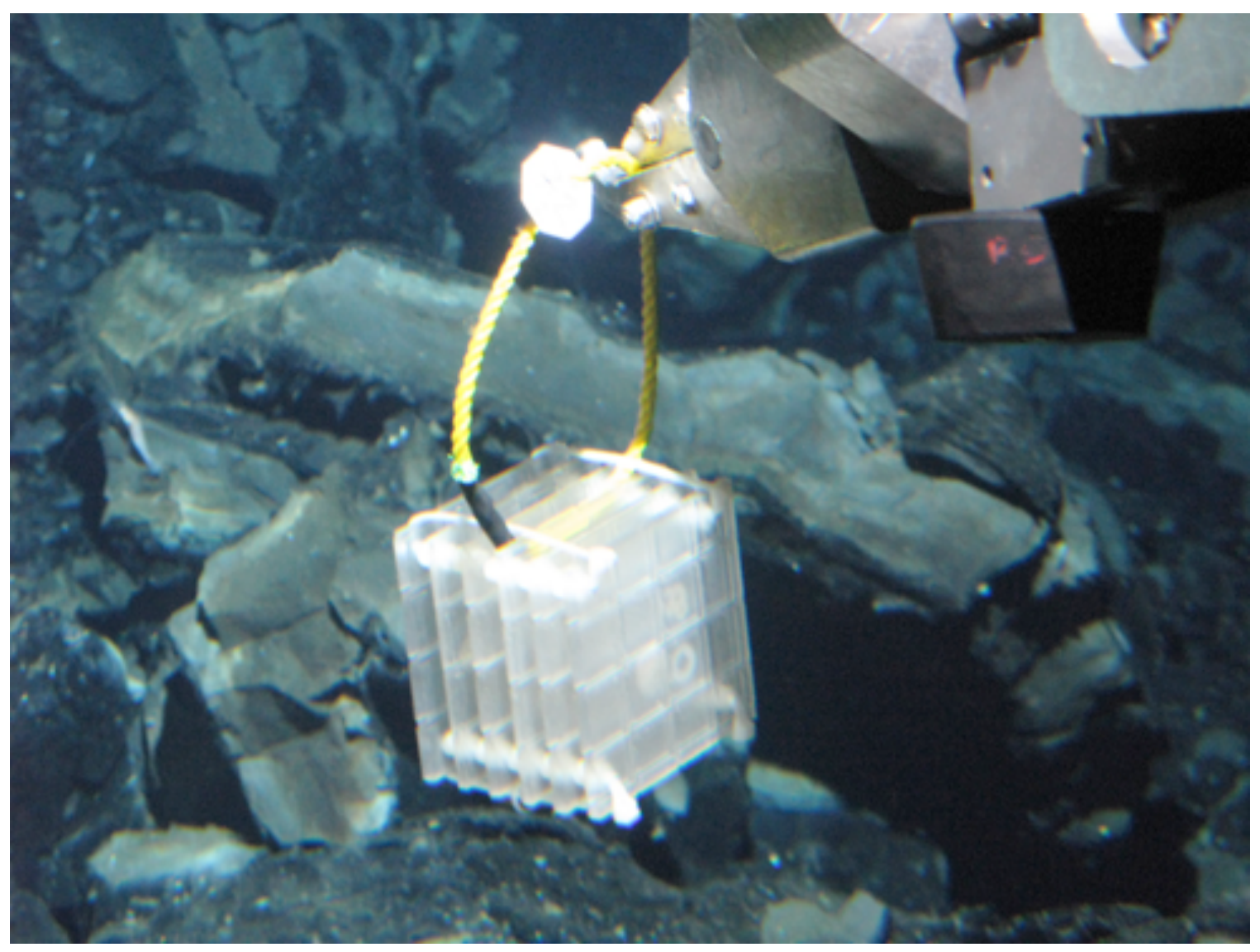


Fig. 3 Frequency of oocyte diameter $(\mu \mathrm{m})$ for Ctenopelta porifera $(\mathrm{a}, \mathrm{b})$ and Lepetodrilus tevnianus (c, d). Samples from December 2006 (unfilled bars), and November 2007 (filled bars). Values pooled from multiple individuals; shown with standard error. $\mathrm{N}$ is the number of individuals sampled and $n$ is total number of oocytes. Arrows indicate size of onset of vitellogenesis.

a

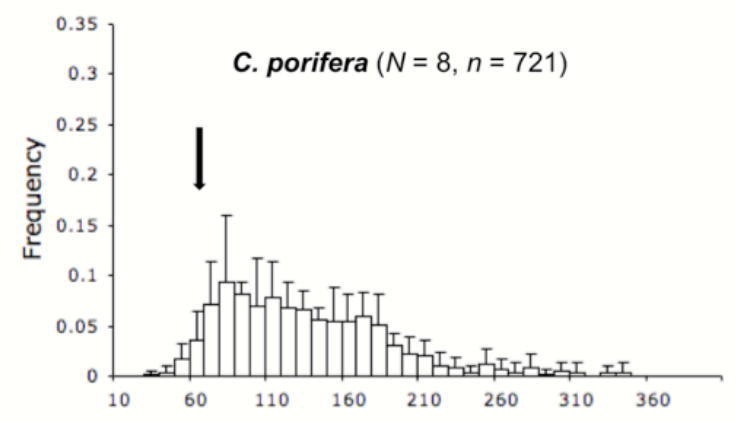

c

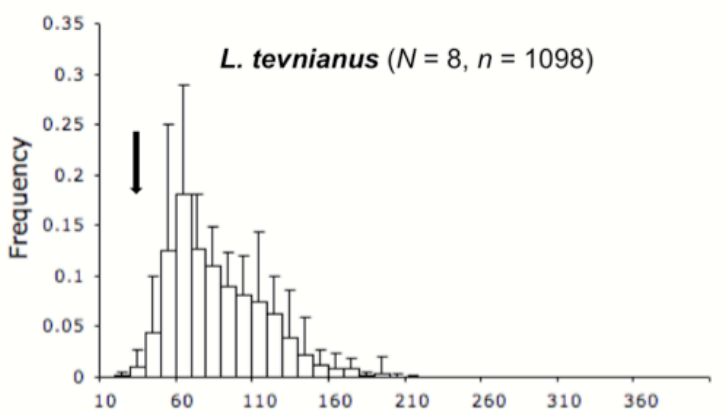

b

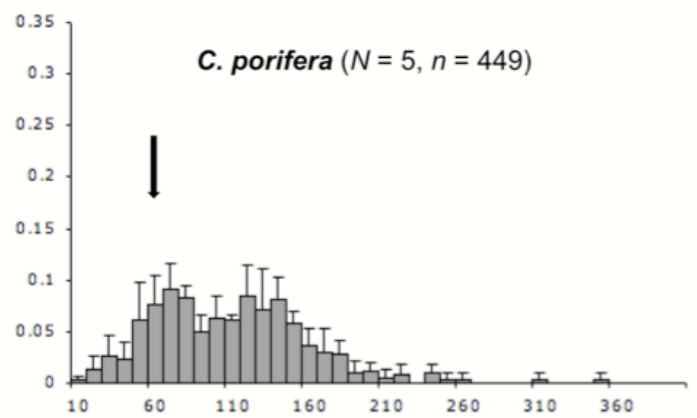

d

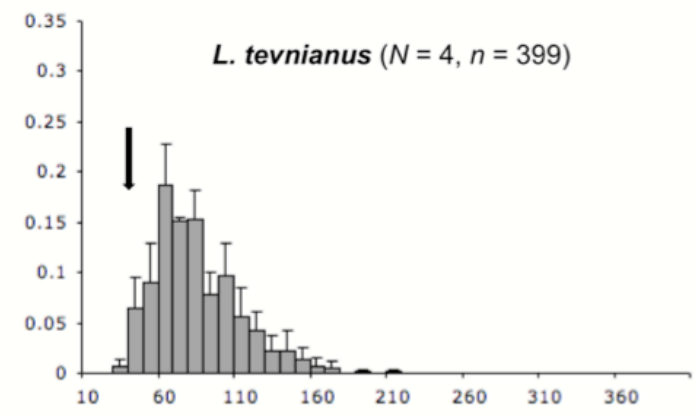

Oocyte Diameter $(\mu \mathrm{m})$ 
Fig. 4 Fecundity (number of vitellogenic oocytes) over a range of shell lengths for Ctenopelta porifera (a) and Lepetodrilus tevnianus (b). Samples from December 2006 (Pvent, unfilled squares) and November 2007 (P-vent, filled squares; V-vent, filled triangles). $n=10$ individuals from each date. Exponential regressions generated for December 2006 (dashed lines) and November 2007 (solid lines). Size at first reproduction represented as a star.
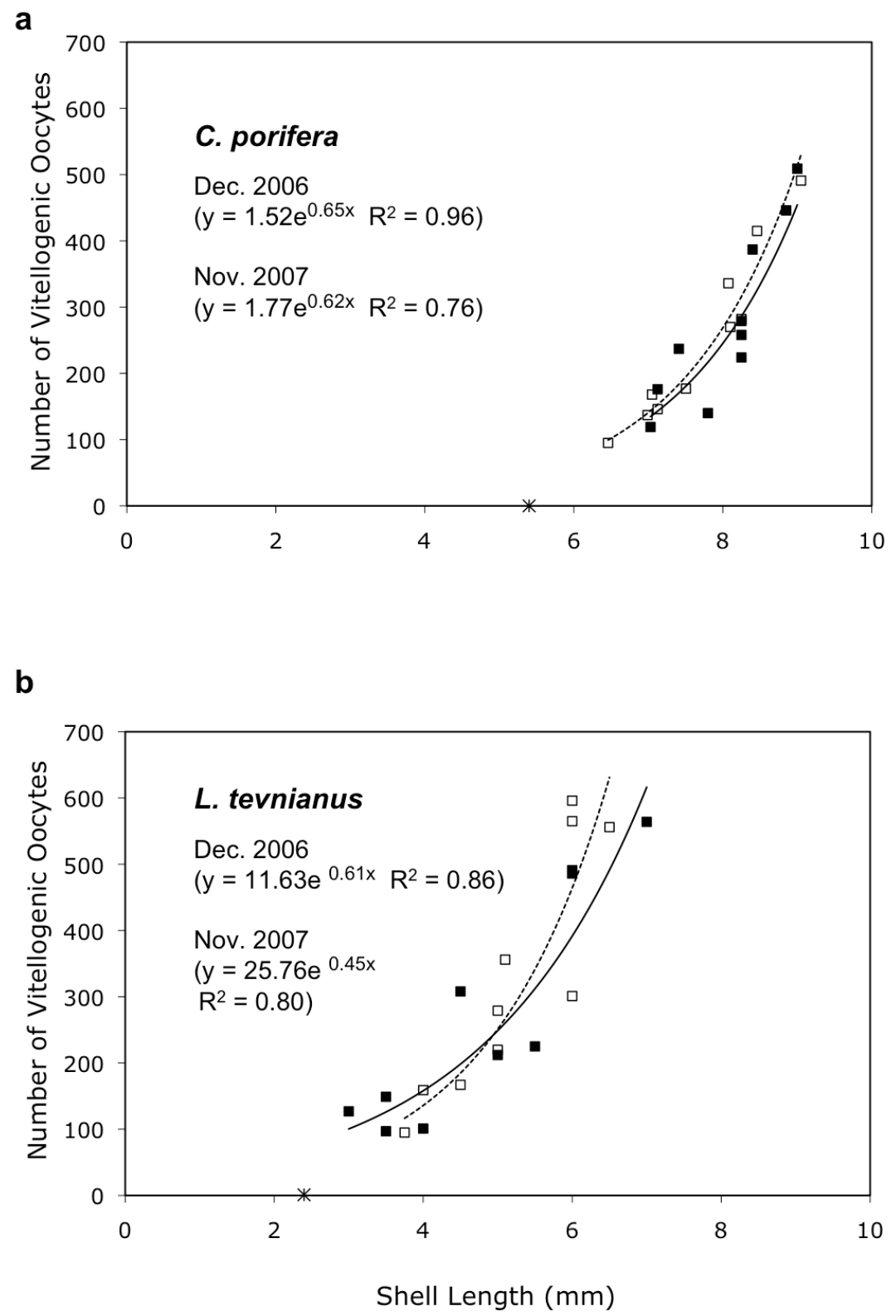
Fig. 5 Frequency of gastropod size in populations of Lepetodrilus tevnianus in December 2006 (a), Ctenopelta porifera in December 2006 (b), and C. porifera in November 2007 (c). Individuals from P-vent (unfilled bars) and V-vent (filled bars).

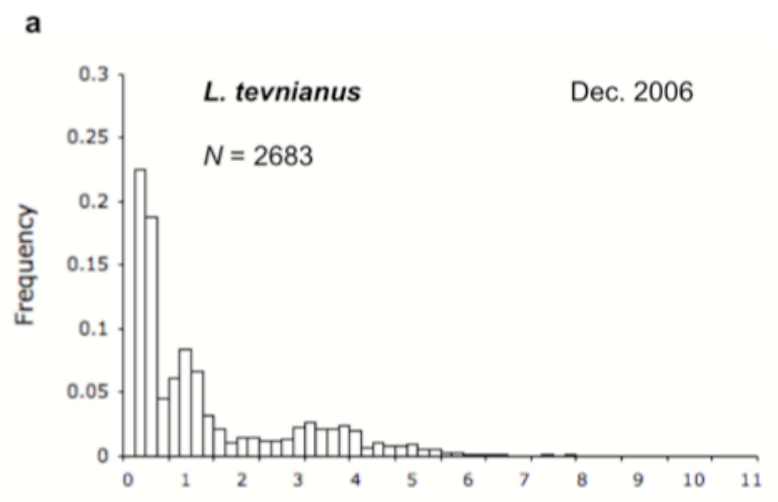

b
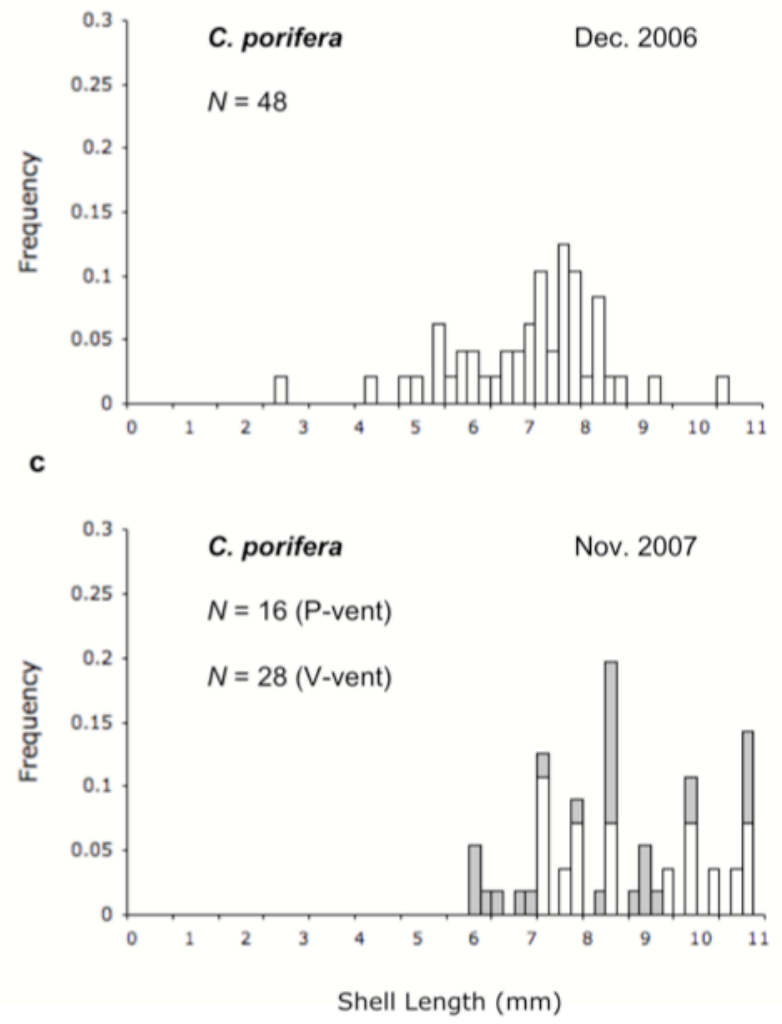


\section{Tables}

Table 1 Ctenopelta porifera and Lepetodrilus tevnianus individuals collected in December 2006 and November 2007 from P-vent and V-vent sites. Total is number recovered on sandwiches. A subset of individuals used for each analysis (reproductive morphology RM, size at first reproduction SFR, oocyte size frequency OSF, and fecundity F) was selected haphazardly from within a size range (Selection criterion). Shell length analyses (SL) used all individuals (All). Additional criterion for all reproductive analyses was that sections were whole and undistorted. Sex of selected individuals was categorized as Male, Female or unknown (Unk).

\begin{tabular}{|c|c|c|c|c|c|c|c|c|}
\hline \multirow[t]{2}{*}{ Date } & \multirow[t]{2}{*}{ Site } & \multirow[t]{2}{*}{ Species } & \multirow[t]{2}{*}{ Total } & \multirow[t]{2}{*}{ Analysis } & \multirow{2}{*}{$\begin{array}{l}\text { Selection } \\
\text { criterion }\end{array}$} & \multicolumn{3}{|c|}{ Number selected } \\
\hline & & & & & & Male & Female & Unk \\
\hline \multirow[t]{10}{*}{2006} & $P$ & C. porifera & 48 & RM & $5.0-10.0 \mathrm{~mm}$ & 10 & 16 & \\
\hline & & & & SFR & $<5.0 \mathrm{~mm}$ & 2 & 2 & \\
\hline & & & & OSF & $7.0-9.0 \mathrm{~mm}$ & - & 8 & \\
\hline & & & & $\mathrm{F}$ & $6.0-10.0 \mathrm{~mm}$ & - & 10 & \\
\hline & & & & SL & All & 10 & 17 & 21 \\
\hline & $\mathrm{P}$ & L. tevnianus & 2683 & $\mathrm{RM}$ & $3.5-7.0 \mathrm{~mm}$ & 14 & 15 & \\
\hline & & & & SFR & $<3.0 \mathrm{~mm}$ & 5 & 5 & \\
\hline & & & & OSF & $3.5-7.0 \mathrm{~mm}$ & - & 8 & \\
\hline & & & & $\mathrm{F}$ & $3.5-7.0 \mathrm{~mm}$ & - & 10 & \\
\hline & & & & SL & All & 17 & 17 & 2649 \\
\hline \multirow[t]{10}{*}{2007} & $\mathrm{P}$ & C. porifera & 16 & RM & $6.0-10.0 \mathrm{~mm}$ & 4 & 12 & \\
\hline & & & & OSF & $7.0-9.0 \mathrm{~mm}$ & - & 4 & \\
\hline & & & & $\mathrm{F}$ & $6.0-10.0 \mathrm{~mm}$ & - & 6 & \\
\hline & & & & SL & All & 4 & 12 & 16 \\
\hline & V & & 28 & RM & $5.0-10.0 \mathrm{~mm}$ & 7 & 7 & \\
\hline & & & & $\mathrm{F}$ & $6.0-10.0 \mathrm{~mm}$ & - & 4 & \\
\hline & & & & SL & All & 7 & 7 & 14 \\
\hline & $\mathrm{P}$ & L. tevnianus & $91^{*}$ & $\mathrm{RM}$ & $6.0-10.0 \mathrm{~mm}$ & 11 & 11 & \\
\hline & & & & OSF & $3.5-7.0 \mathrm{~mm}$ & - & 5 & \\
\hline & & & & $\mathrm{F}$ & $3.5-7.0 \mathrm{~mm}$ & - & 10 & \\
\hline
\end{tabular}

* Individuals subsampled haphazardly from total on sandwiches to match SL range (2.0-7.0 mm) from 2006. This subsampling precluded analysis of size frequency distribution (SL) for L. tevnianus from 2007 
Table 2 Maximum likelihood (ML) estimates of oocyte diameter parameters from the EM mixture model analysis for C. porifera and L. tevnianus. Oocyte diameter data (logtransformed; $n=$ total number of oocytes) pooled among individuals from 2006 and 2007 samples. Estimates are mean $\mu$ and variance $\sigma^{2}(\log \mu \mathrm{m})$ for the null hypothesis $H_{\mathrm{o}}$ (that $\log$ oocyte diameter follows a single normal distribution), and means $\mu_{1}$ and $\mu_{2}(\log \mu \mathrm{m})$, standard deviation $\sigma(\log \mu \mathrm{m})$, and probability $\pi$ that an observation belongs to the first component, for the alternative hypothesis $H_{1}$ (that log oocyte diameter follows a mixture of two normal distributions with the same variance). $\log L_{0}$ and $\log L_{1}$ are the maximized $\log$ likelihoods under $H_{\mathrm{o} 1}$ and $H_{1}$, respectively.

\begin{tabular}{lllllllllll}
\hline Species & Year & $n$ & $\mu$ & $\sigma$ & $\log L_{\mathrm{o}}$ & $\mu_{1}$ & $\mu_{2}$ & $\sigma$ & $\pi$ & $\log L_{1}$ \\
\hline C. porifera & 2006 & 721 & 4.7 & 0.4 & 234.3 & 4.4 & 5.0 & 0.30 & 0.44 & 242.0 \\
& 2007 & 448 & 4.8 & 0.4 & 203.8 & 4.4 & 5.0 & 0.27 & 0.35 & 210.3 \\
& & & & & & & & & & \\
L.tevnianus & 2006 & 1098 & 4.3 & 0.4 & 470.5 & 4.0 & 4.6 & 0.27 & 0.49 & 484.2 \\
& 2007 & 399 & 4.3 & 0.4 & 203.1 & 4.0 & 4.4 & 0.30 & 0.49 & 203.4 \\
\hline
\end{tabular}

Table 3 Maximum likelihood (ML) estimates of oocyte diameter parameters from the EM mixture model analysis, fit under the null hypothesis $H_{0}$, that the parameters of the two-component normal mixture distribution were the same in both years for $C$. porifera and L. tevnianus. Data transformations and parameters as in Table 2.

\begin{tabular}{llllll}
\hline Species & $\mu_{1}$ & $\mu_{2}$ & $\sigma$ & $\pi$ & $\log L_{\mathrm{o}}$ \\
\hline C. porifera & 4.4 & 5.0 & 0.29 & 0.39 & 444.0 \\
L. tevnianus & 4.0 & 4.6 & 0.27 & 0.50 & 682.4 \\
\hline
\end{tabular}


Table 4 Summary of known reproductive traits of hydrothermal vent gastropods including members of the families Lepetodrilidae (Lepetodrilus atlanticus, L. fucensis, $L$. cristatus, L. elevatus, L. ovalis, L. pustulosus, L. tevnianus) and Peltospiridae (Rhynchopelta concentrica, Ctenopelta porifera). Oocyte diameters listed as maximums or ranges. EPR East Pacific Rise, MAR Mid-Atlantic Ridge, JdFR Juan de Fuca Ridge, Exp Explorer Ridge, GR Galapagos Rift.

\begin{tabular}{|c|c|c|c|c|c|}
\hline \multirow[t]{2}{*}{ Species } & \multirow[t]{2}{*}{ Date } & \multirow{2}{*}{$\begin{array}{l}\text { Locatio } \\
\text { n }\end{array}$} & \multicolumn{2}{|c|}{ Oocyte Size $(\mu \mathrm{m})$} & \multirow[t]{2}{*}{ Source } \\
\hline & & & $\begin{array}{l}\text { Onset of } \\
\text { vitellogenes } \\
\text { is }\end{array}$ & $\begin{array}{l}\text { Vitellogenic } \\
\text { (Max.) }\end{array}$ & \\
\hline \multicolumn{6}{|l|}{$\begin{array}{l}\text { Family } \\
\text { Lepetodrilidae }\end{array}$} \\
\hline L. atlanticus & $\begin{array}{l}\text { March- } \\
\text { April } 2001\end{array}$ & MAR & $35-40$ & 92 & $\begin{array}{l}\text { Pendlebury } \\
(2005)\end{array}$ \\
\hline L. fucensis & $\begin{array}{l}\text { July } 2001 \\
\text { July - } \\
\text { Sept. } 1984\end{array}$ & $\begin{array}{l}\text { JdFR, } \\
\text { Exp }\end{array}$ & $35-45$ & $\begin{array}{l}60-110 \\
100-140\end{array}$ & $\begin{array}{l}\text { Kelly and } \\
\text { Metaxas (2007) } \\
\text { Fretter (1988) }\end{array}$ \\
\hline L. cristatus & $\begin{array}{l}\text { March } \\
1984\end{array}$ & EPR & $30-35$ & $140-150$ & Fretter (1988) \\
\hline L. elevatus & $\begin{array}{l}\text { Dec. } 2001 \\
\text { April - } \\
\text { May } 1979\end{array}$ & EPR & $30-35$ & $\begin{array}{l}84 \\
74-95\end{array}$ & $\begin{array}{l}\text { Pendlebury } \\
(2005) \\
\text { Berg (1985) }\end{array}$ \\
\hline L. ovalis & Dec. 2001 & EPR & $30-35$ & 87 & $\begin{array}{l}\text { Pendlebury } \\
(2005)\end{array}$ \\
\hline L. pustulosus & $\begin{array}{l}\text { March } \\
1984 \\
\text { Dec. } 2001 \\
\text { April - } \\
\text { May 1979 }\end{array}$ & EPR & $30-35$ & $\begin{array}{l}230 \\
84 \\
83-204\end{array}$ & $\begin{array}{l}\text { Fretter (1988) } \\
\text { Pendlebury } \\
(2005) \\
\text { Berg }(1985)\end{array}$ \\
\hline L. tevnianus & Dec. 2006 & EPR & $35-40$ & $130-150(210)$ & This study \\
\hline \multicolumn{6}{|c|}{ Family Peltospiridae } \\
\hline R. concentrica & $\begin{array}{l}\text { Dec. } 2001 \\
\text { April - } \\
\text { May } 1979\end{array}$ & EPR & $50-60$ & $\begin{array}{l}90(184) \\
132-152\end{array}$ & $\begin{array}{l}\text { Pendlebury } \\
(2005) \\
\text { Berg (1985) }\end{array}$ \\
\hline C. porifera & Dec. 2006 & EPR & $60-70$ & $230-250(330)$ & This study \\
\hline
\end{tabular}




\section{Appendix A - Mixture-model analysis of oocyte size}

In order to determine whether different cohorts could be distinguished in the size distributions, an Expectation-Maximization (EM) algorithm (McLachlan 1987;

McLachlan and Peel 2000) was used to conduct a mixture-model analysis on the data to test for two normal distributions of oocyte size. As an initial step, for both C. porifera and L. tevnianus and both sampling years, we tested the null hypothesis $H_{\mathrm{o}}$, that log oocyte size follows a single normal distribution against the alternative hypothesis $H_{1}$, that it follows a mixture of two normal distributions with the same variance. The likelihood ratio (LR) test, which is described in McLachlan and Peel (2000), involves fitting by maximum likelihood (ML) under both hypotheses and forming the LR statistic - 2( $\left(\log L_{o}-\log L_{1}\right)$ where $\log L_{\mathrm{o}}$ and $\log L_{1}$ are the maximized $\log$ likelihoods under $H_{\mathrm{o}}$ and $H_{1}$, respectively. Under $H_{\mathrm{o}}$, the model contains two parameters: the mean $\mu$ and variance $\sigma^{2}$. The ML estimates of these parameters are simply the sample mean and variance (with divisor $n$ ). Under $H_{1}$, the model contains four parameters: the means $\mu_{1}$ and $\mu_{2}$ of the two components, their common variance $\sigma^{2}$, and the probability $\pi$ that an observation belongs to the first component. The ML estimates of these parameters can be found by the EM algorithm (McLachlan 1987). We then proceeded to test for both species the null hypothesis $H_{\mathrm{o}}$, that the parameters of the two-component normal mixture distribution were the same in both years (for each species) against the alternative hypothesis $H_{1}$ that they differed.

The oocyte size distributions (pooled over multiple individuals) of C. porifera (Figure 3a, b) and L. tevnianus (Figure 3c, d) appeared to have more than a single normally distributed size-component. The mixture-model analysis demonstrated evidence 
of two size-components in the oocyte size frequency data for both species (Table 2), possibly reflecting two cohorts of oocytes. For this size range of samples, the likelihood ratio (LR) statistic under $H_{\mathrm{o}}$ has an approximate chi squared distribution with 2 degrees of freedom (McLachlan 1987). Using this approximation, $H_{\mathrm{o}}$ is rejected $(\mathrm{P}<0.01)$ in all cases except for L. tevnianus samples from November 2007. We therefore assumed conservatively that in all cases the distribution of log size follows a two-component normal mixture. This is a conservative assumption in the sense that if it is incorrect, it will not affect the validity of the test. For both species the null hypothesis $H_{0}$, that the parameters of the two-component normal mixture distribution were the same in both years, was tested against the alternative hypothesis $H_{1}$. The ML estimates of the parameters under $H_{1}$ are given in the Table 2 and the overall $\log$ likelihoods -452.3 for C. porifera and 687.6 for L. tevnianus - are given by the sum of the log likelihoods in the appropriate rows. In the case of fitting under $H_{\mathrm{o}}$, the LR statistic has an approximate chi squared distribution with 4 degrees of freedom. The results for fitting under $H_{\mathrm{o}}$ are shown in Table 3.

The null hypothesis was rejected for both species $(\mathrm{P}=0.002$ for $C$. porifera and $\mathrm{P}$ $=0.03$ for L. tevnianus). It is worth pointing out that, as a result of the large sample sizes, this test is quite powerful and even small differences among the parameters may lead to the rejection of $H_{0}$. It appears in this case that the main difference between years is in the proportion of the first component of the mixture distribution for C. porifera. 


\section{Appendix B - Comparison of fecundity-size relationship between years}

For both Ctenopelta porifera and Lepetodrilus tevnianus, we used a regression model assuming a negative-binomial distribution to test for statistically significant differences of fecundity between years. Let $Y_{j t}$ be the number of vitellogenic oocytes produced by individual $j(j=1,2, \ldots, n)$ in year $t(t=1,2)$ and let $x_{j t}$ be the shell length of this individual. We assume that $Y_{j t}$ is related to $x_{j t}$ by the regression model:

$$
\ln Y_{j t}=\beta_{o t}+\beta_{1 t} x_{j t}+\varepsilon_{j t}
$$

where $\varepsilon_{j t}$ is a normal error with mean 0 and variance $\sigma^{2}$. Interest centers on testing the null hypothesis $H_{o}$ that the unknown regression parameters $\beta_{o t}$ and $\beta_{1 t}$ are the same in both years against the alternative hypothesis $H_{1}$ that they are different.

The $F$ statistic for testing $H_{o}$ against $H_{1}$ is:

$$
F=\frac{\left(R S S_{o}-R S S_{1}\right) / 2}{R S S_{1} /(n-4)}
$$

(Seber and Lee 2003) where $R S S_{o}$ is the residual sum of squares from fitting the model in (1) by ordinary least squares to the data pooled over the two years and $R S S_{1}$ is the residual sum of squares from fitting the model to the data for each year separately. Under $H_{o}, F$ has an $F$ distribution with 2 degrees of freedom in the numerator and $n-4$ degrees of freedom in the denominator. For C. porifera, the estimated regression parameters for each year separately are:

$$
\begin{array}{ll}
\hat{\beta}_{o 1}=0.42 & \hat{\beta}_{11}=0.65 \\
\hat{\beta}_{o 2}=0.57 & \hat{\beta}_{12}=0.62
\end{array}
$$

and the estimates for the pooled data are: 


$$
\hat{\beta}_{o}=0.91 \quad \hat{\beta}_{1}=0.59
$$

The value of $F$ is 0.13 with a $\mathrm{P}$ value of 0.88 . In this case, the null hypothesis cannot be rejected. For L. tevnianus, the analogous results are as follows:

$$
\begin{array}{ll}
\hat{\beta}_{o 1}=2.45 & \hat{\beta}_{11}=0.61 \\
\hat{\beta}_{o 2}=3.25 & \hat{\beta}_{12}=0.45 \\
\hat{\beta}_{o}=2.45 & \hat{\beta} 1=0.60
\end{array}
$$

In this case, the value of $F$ is 5.51 with a $\mathrm{P}$ value of 0.02 , so that the null hypothesis can be rejected. 


\section{Appendix C - Reproductive morphology}

\section{Ctenopelta porifera}

The gonads were located in the posterior region of the animals. The ovary occupied approximately one-fourth of the total body length and was located predominantly on the right side of the body as viewed dorsally, just posterior to the foot muscle. The stomach and digestive gland lay to the left of the ovary and extended just over the left foot muscle (Fig. A1a). Deeper, more ventral sectioning revealed that the ovary extended towards the gills. At its dorsal-most point, the ovary stretched posteriorly away from the center of the body into a "tail" shape that was visible macroscopically when the shell had been removed.

The location of the gonad in males was predominantly on the right side of the body, posterior to the right foot muscle, like the ovary of the female. However, deeper in the body, the spermatozoa generally extends further towards the gills than does the ovary. The testis is composed of multiple elongated seminferous tubules (acini) with spermatagonia and spermatocytes lining the edges of the tissue walls. The spermatids cluster in the center of each acinus with their tails staining the center pink (Fig. A2a).

\section{Lepetodrilus tevnianus}

Cross-sectioning revealed that L. tevnianus also is gonochoristic. In immature individuals, gonads were difficult to distinguish from the digestive gland. In more mature specimens, the gonad was a distinct structure and expanded laterally towards the right side of the body. The gonad of both females and males was located in the same general 
area of the body, dorsal to the musculature of the foot, ventral to the stomach and digestive glands.

Light histological sections of L. tevnianus stained with haematoxylin and eosin (Fig. A1c) illustrate that the ovary occupies a large volume of the gastropod (approximately one-third) and that oocytes are tightly packed throughout the ovary. In dorsal-most sections, only a small portion was visible at the posterior end of the body. Deeper sections reveal the ovary was visible on the right side extending into the visceral mass and mantle cavity, underlying the stomach and digestive glands.

The general shape of the gonads in males, and the location relative to the stomach, digestive gland and foot, were similar to those of the ovary in females (Fig. A2b). The testis takes up approximately one third of the body volume and is composed of acini. Spermatagonia and spermatocytes line the walls of the testicular acini. Due to their high concentration of nucleic material, spermatagonia, spermatocytes and spermatid nuclei are stained dark purple in haematoxylin and eosin stains. As the spermatocytes develop, they move towards the center of the tubule where they divide into spermatids. The mature sperm collect in the central region (stained pink in Fig. A2b) of the acini for transport out of the gastropod. 
Fig. A1 Light histology of adult female gonads in Ctenopelta porifera $(\mathbf{a}, \mathbf{b})$ and Lepetodrilus tevnianus (c). (a) Section of ovary showing oogonia (OO), pre-vitellogenic oocytes (PV), vitellogenic oocytes (VO), an oocyte nucleus (N), and stomach (S). (b) Visceral mass including ovary (with pre-vitellogenic (PV) and vitellogenic (VO) oocytes), foot muscle (FM) and stomach (S). (c)Visceral mass including digestive gland (DG), stomach (S), foot muscle (FM) and ovary (with an oocyte nucleus (N), oogonia (OO), pre-vitellogenic (PV), vitellogenic (VO) oocytes).

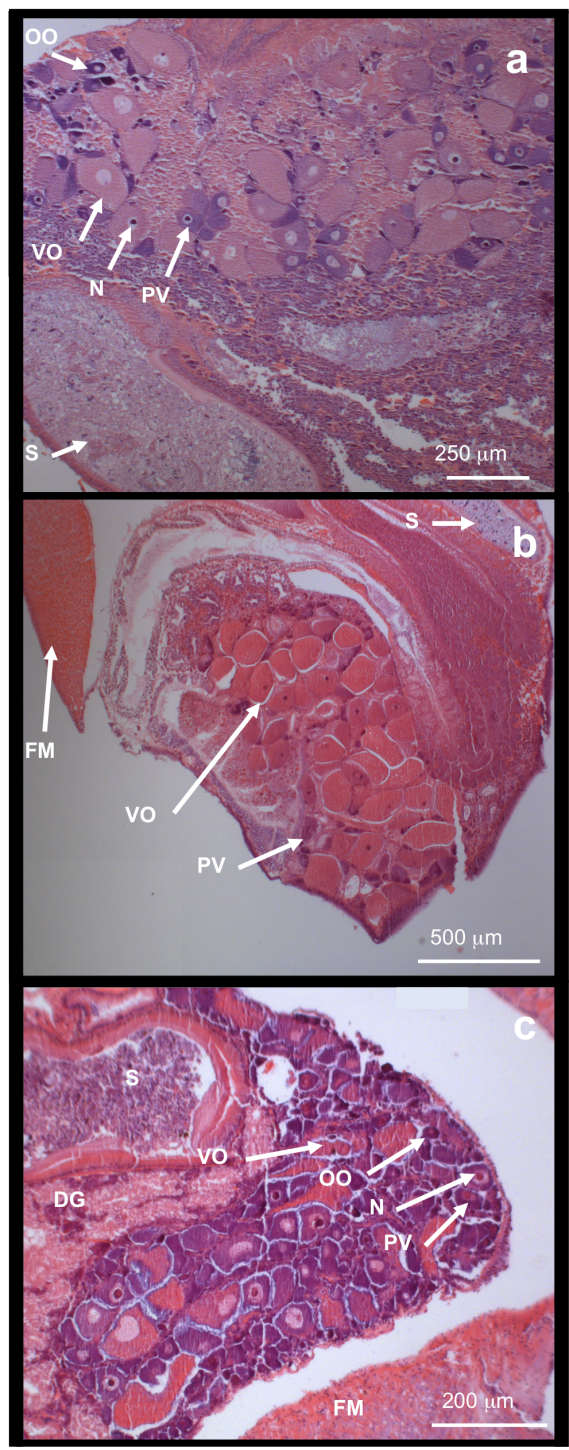


Fig. A2 Light histology of adult male gonads in Ctenopelta porifera (a) and Lepetodrilus tevnianus (b). (a) Section of visceral mass showing testis (T), digestive gland (DG), connective tissue (CT), spermatocytes (SPC), and spermatozoa (SPZ). (b) Section of visceral mass showing testis (T), digestive glad (DG), stomach (S), spermatozoa (SPZ), and foot muscle (FM).

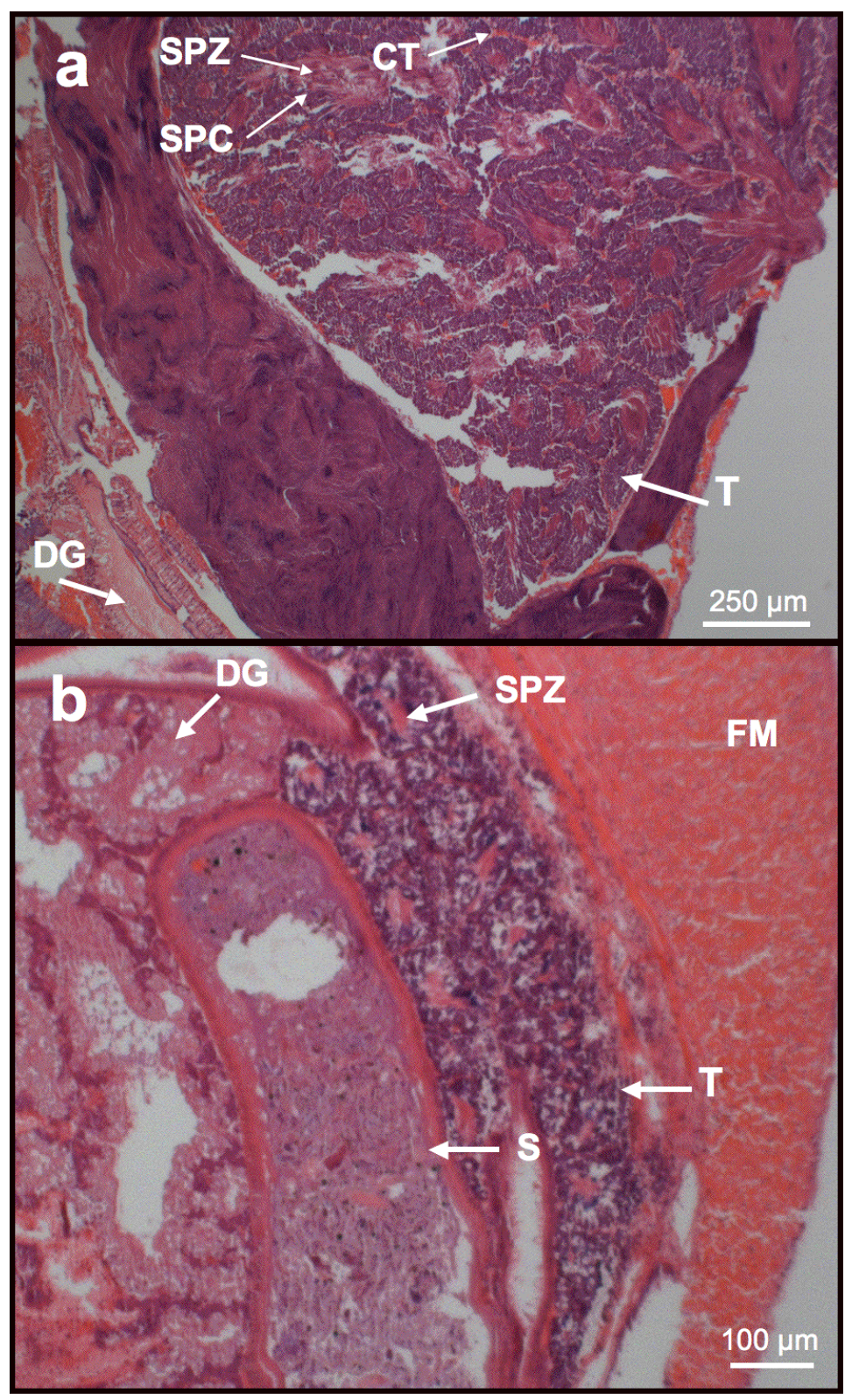

